\section{Italian Industry in the}

The Manufacture of Artillery by the Ansaldos,

\author{
By Arthur Benington
}

WHEN the Royal Italian Mission was in America remark that what Italy had been able to do in a military way against Austria was due to two men more than to anything else, and that these two men were the Commendatori Pio and Mario Perrone, principal directors and stockholders of Giovanni Ansaldo \& Co. of Genoa who had kept the army and navy supplied with a constant stream of guns and ammunition of all sizes.

And General Dallolio, Italian Minister of Munitions, made a statement in December that the munition factories of Italy had within one month atter the terrible disaster at Caporetto made up the entire loss of guns and ammunition that followed that defeat. The Italian War Office has never told how many guns were lost there, but the Germans and Austrians claimed to have taken half the total supply of the Italian army. The total supply of the Italian army. Th exaggerated, but it is safe to say that more than a thousand cannon fell into their hands, and vast
stores of ammunition. The chief labor of replenishing this depleted armament fell upon the Ansaldo company, whose factories at Genoa hummed as they had never hummed before with the rush of work. Day and night their furnaces work. Day and night their furnace roared and their hammers clanged, as shift followed shift of skilled mechanics. And their proving grounds banged in cessantly like a section of the battle line as battery afte battery of naval cannon, mortars, field pieces, bombthrowers and siege guns was placed in position and tested before being rushed to the front.

The photographs on these pages were taken in the Ansaldo works; they might be multiplied a hundred times and scarcely give an adequate idea of the tre mendous output of guns of all sizes that is ever pouring from the company's work shops. A beautiful and im pressive contrast is that pressive contrast is that cannon and the little trench mortar that can be carried in one man's hands-the Goliath and the David of artillery. The former is the largest gun turned out by largest gun turned out by the company; it throws shell approximately fif teen inches in diameter and has hitherto been used exclusively on battleships; but this war has brought large caliber artillery right into the field in all armies, and the 381-millimeter gun is now used by the Italians on land used by the Italians on land

cellent idea of its size can be had from the photograph that shows three of them unmounted in one of the factories, with a man standing between them.

This gun is so heavy that it cannot be hauled about like an ordinary field gun, even with the powerful tractors that are now being used for weight if on a carriage would ruin the best of roads and might easily result in breakin But it can be run about on railroads withou danger if mounted on trucks that will bear it weight. One of the most interesting of the photographs on this page is that of the railway trucks designed and built by the Ansaldo company especilly for by the Ansaldo cc this gun. It would be more interestin ing. There are three trucks, arranged in such a way that the central one, with
10 wheels, carries most of the weight,

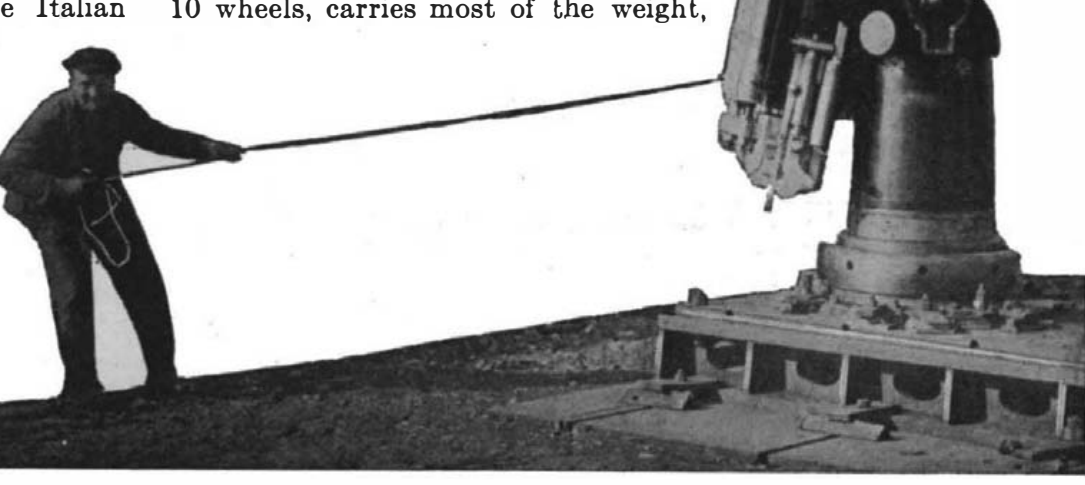

Firing a 76-millimeter anti-aircraft gun through them and getting the gun itself stuck. possible to bring this gun up as near to the enemy's line as a railroad can safely be built and to haul it away quickly to security in case of a serious retreat. This impressive triple-truck gun carriage is the invention of the company's engineers. Without it, these 15 -inch cannon could be used only on warships.

\title{
War
}

\author{
the Genoese Krupps
}

The heaviest mortars built by the company are the 260-millimeter of which a battery is pictured in one of the most striking of the photographs, and of which a single specimen is shown on its carriage in the position in which it is moved from one point to another. It will be observed that the ponderous barrel of the mortar, with a part of its mount, slides backward and downward upon the main part of the carriage, thus occupying little space and making transporteasy. Within a few moments and by the turning of a few cranks the giant gun is pushed forward into its position for firing. Thus a mortar that fires a shell almost $101 / 4$ inches in diameter becomes a mobile gun that can be rushed from one part of the front to another.

Little less impressive are the 210 millimeter mortars on their caterpillarwheeled carriages. These throw a heavy shell a short distance by means of a large charge of quick-burning powder. If great length of range were desired it would be necessary to lengthen the barrel of the gun so that slow firing powder, exerting an ever-increasing pressure while the projectile is passing out, could be used.

Leaving the very heavy guns which are being employed as field pieces for the firet time in this war, we come to the usual field pieces, employed in such enormous numbers by all the armies. Photographs but transmits it at either end to the smaller trucks, each are shown of the Ansaldo company's 102-, 149- and 152of which has 12 wheels. This arrangement makes it millimeter guns in several typical positions. The easy for the gun to be hauled along railroad tracks even lighter of these, which fire a shell of about four inches in with sharp curves. It is a most ingenious device, ex- diameter, are among the most simple in construction of tremely. simple but perfectly effective. It makes it all guns. They are mounted in several ways, but the

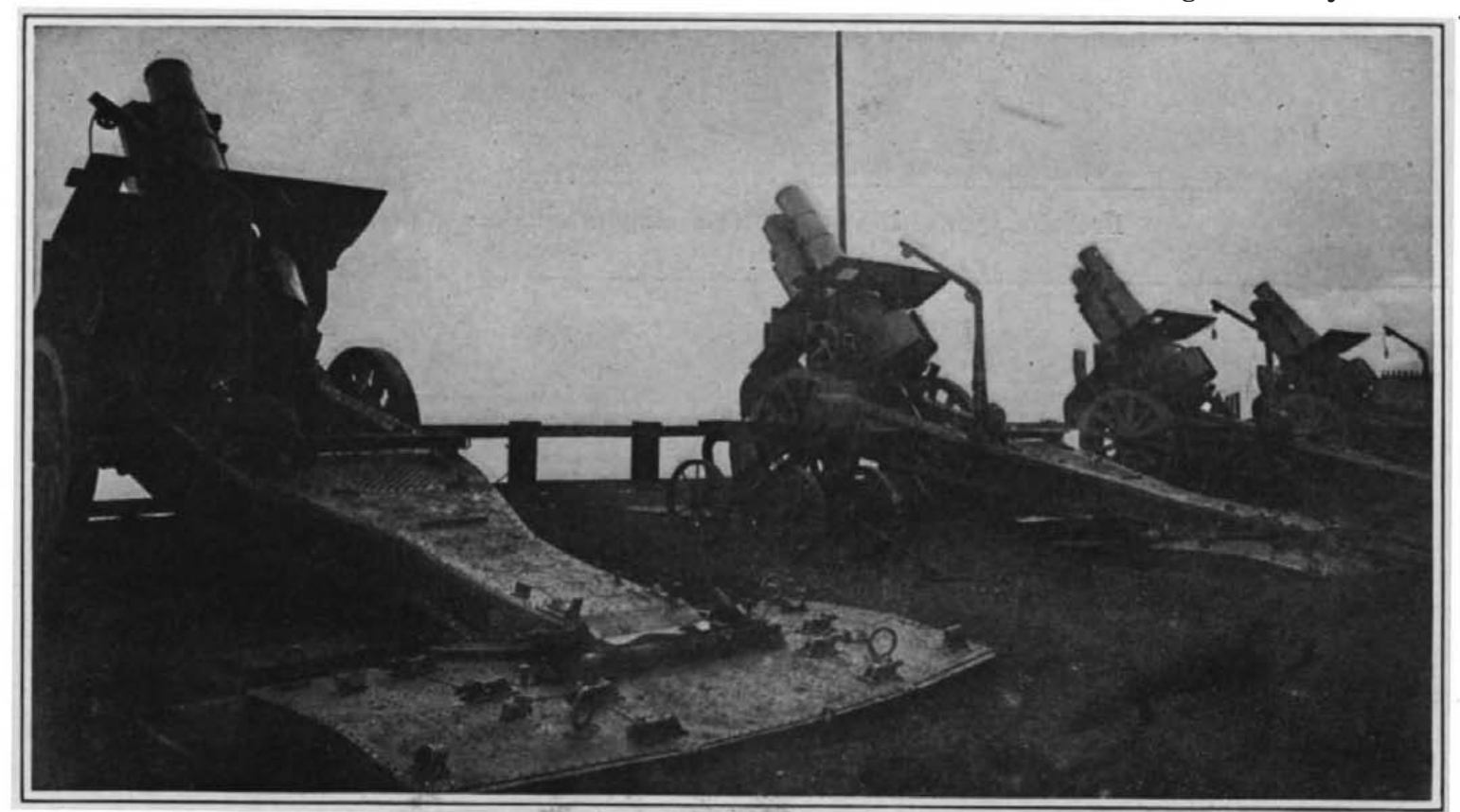

battery of 260 -millimeter mortars in one of the forts near Genoa specially favored mount in the Italian army is the automobile. These auto-batteries make use of ro horses; the guns themselves are on automobile carriages with seats for two gunners, and the gun crews accompany them in motor-camions and on motorcycles. The result is the acme of mobility. Two of the photographs show these guns, one on the march, the other in position for firing, while a third shows a rear view of one of the same guns on an ordinary carriage with its breech open for loading. The shell having been placed, ore turn of the handle to the right drives a heavy slide over the breech and the gun is fired. Another simple turn opens the breech again ready for reloading.

There is little difference between these and the 152 -

milingeter guns: they have the same general plan of using the recoil for dropping the barrel back into position for loading and of almost telescoping the gun on its carriage when necessary to move it.

The anti-aircraft guns are an entirely different type. Mobility is not always their essential, for they are in-

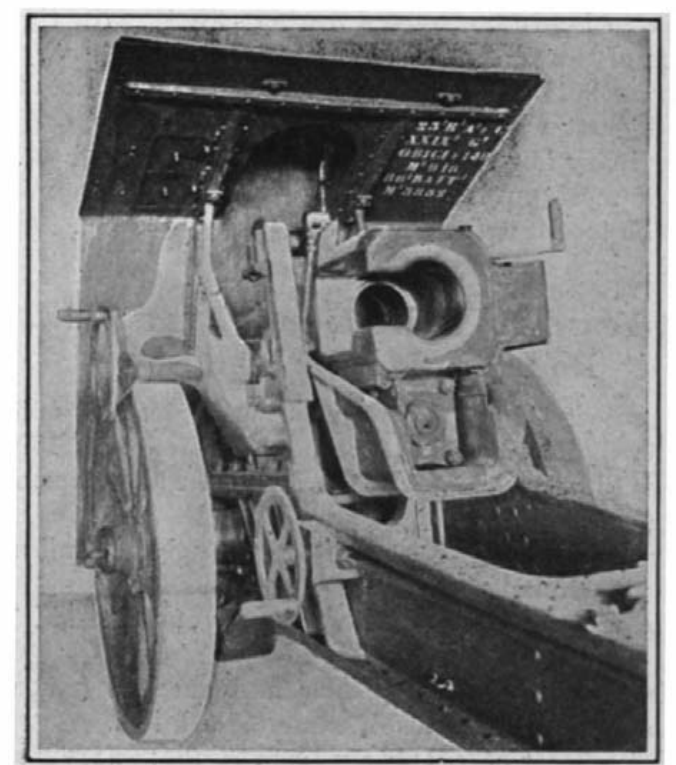

The breech of a 149-millimeter field piece

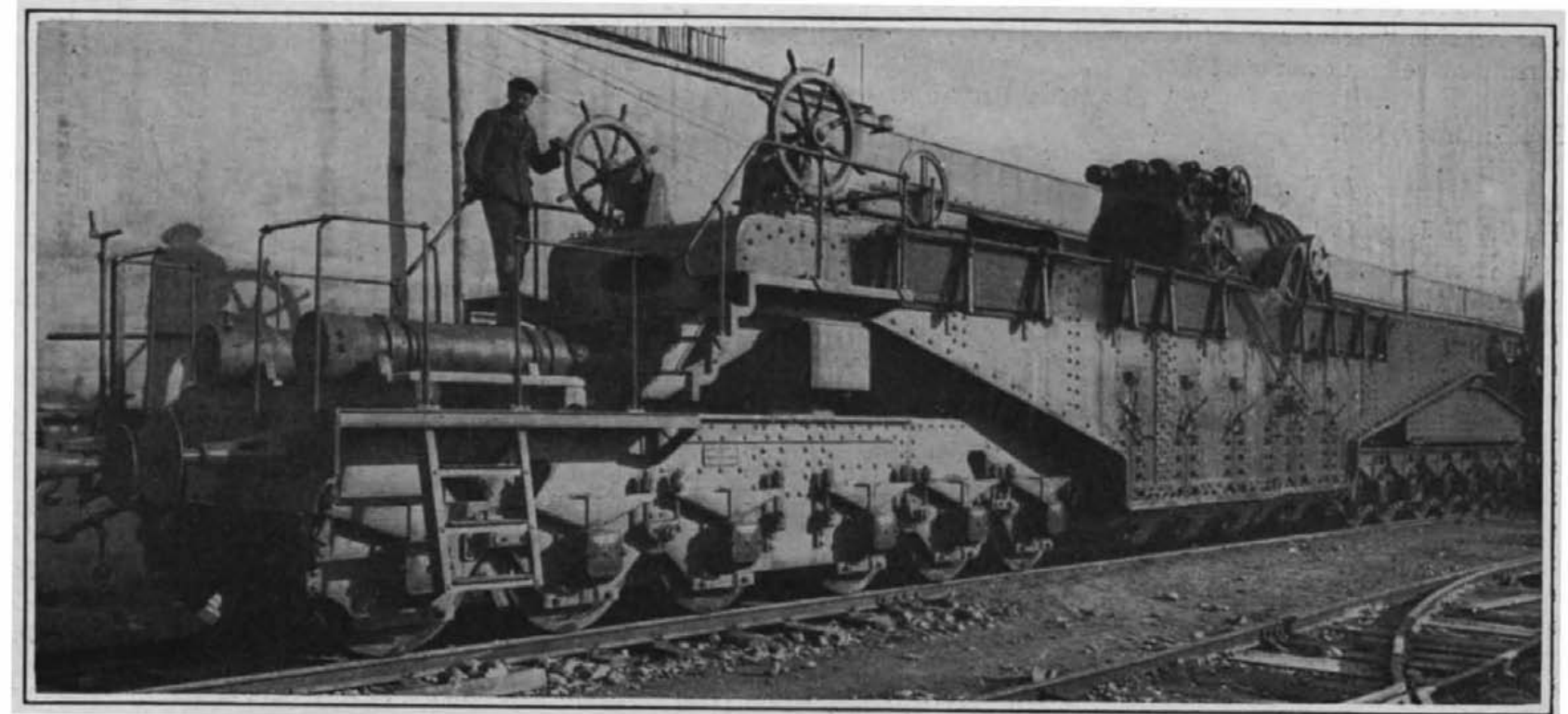

The railroad carriage mount on which a 381-millimeter, 40-caliber gun goes into battle and from which its fire is directed upon the enemy 


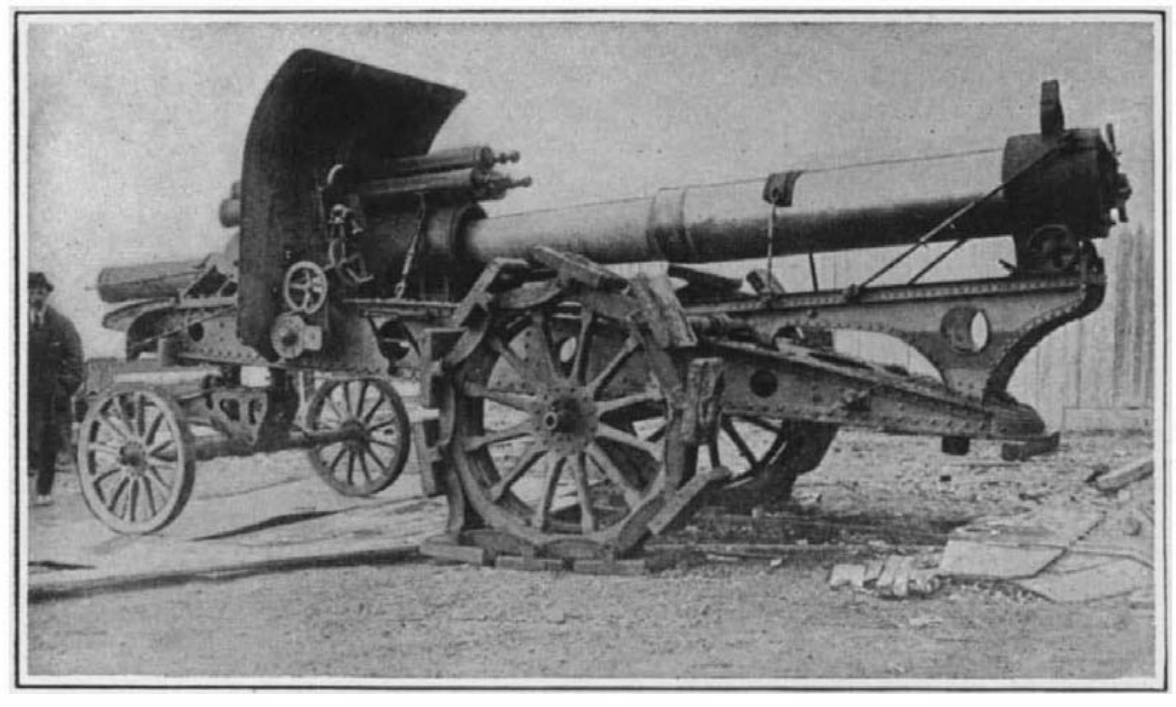

A 152-millimeter gun on its carriage in position for transport

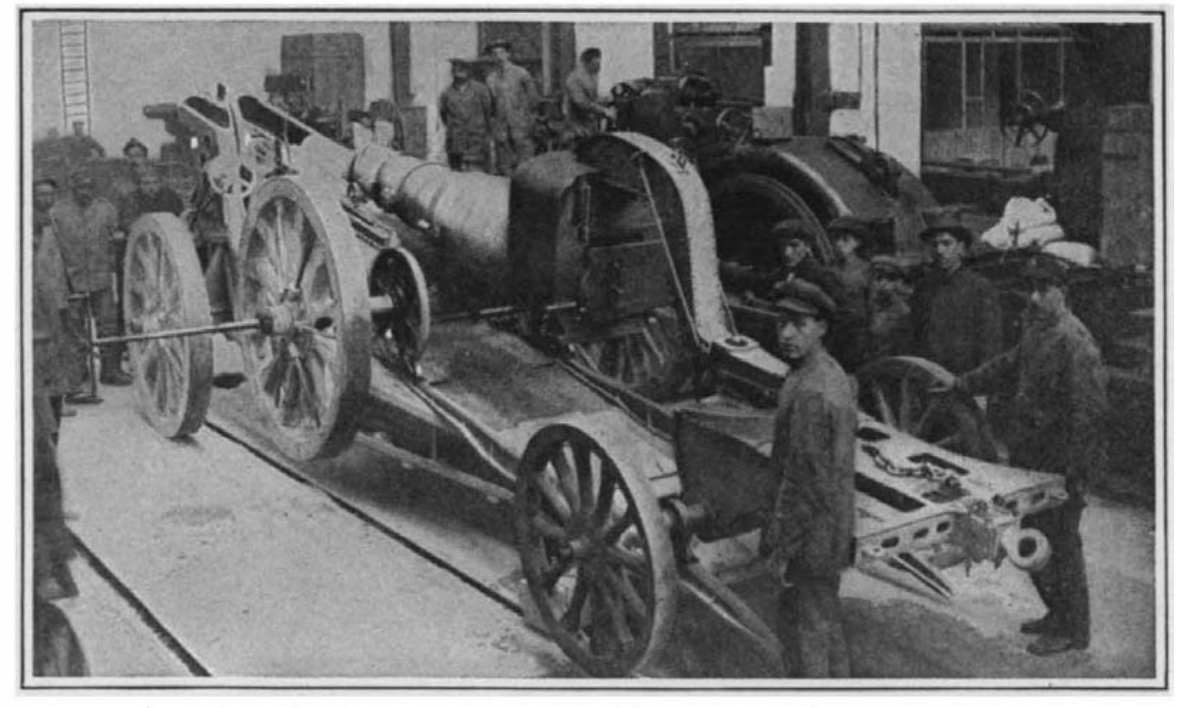

Method of mounting a 260-millimeter gun for transport tended principally to defend cities against raids from the air and are permanently stationed. The greater the distance an anti-aircraft gun can fire the better. Therefore they are of the long-barrelled type, most of them being $\mathbf{4 5}$ calibers long, on stationary turret-like stands, on which they can be turned in all directions. Their barrels slip back with the recoil and are thrown forward again before firing.

In comparison with these monsters the trench bomb-throwers seem like playthings. They can be carried by one man without much difficulty, and are really nothing but tiny mortars, intended to throw bombs a few hundred feet. This form of warfare is a novelty of this campaign. It grew out of the throwing of hand grenades, long supposed to have been obsolete, but brought into vogue again by trench warfare.

The Ansaldo company's shops where these cannon are forged seem to the rare and highly privileged visitor like the antechamber of the front line trenches. A hundred feet overhead pass silently the electrically drawn wagons of the aerial railroad bearing their loads of metal. Two hundred feet overhead the arms of the cranes reach out and seize the material. Armor plates or rough-forged tubes for cannon swing aloft, held by the powerful magnets that serve instead of grappling hooks at the end of the chains. Furnaces with blasts of air entering at 800 degrees Centigrade and heated to 1,500 degrees devour raw materials and pour forth rivers of liquid steel, sputtering sparks, into the molds that form the ingots. These furnaces pour forth steel that is cast into 150-ton ingots for armor plate, barrels of cannon and small arms.

In a vast building, more than 2,000 feet long and nearly 1,000 feet wide, are cannon returned from the front to be repaired, for

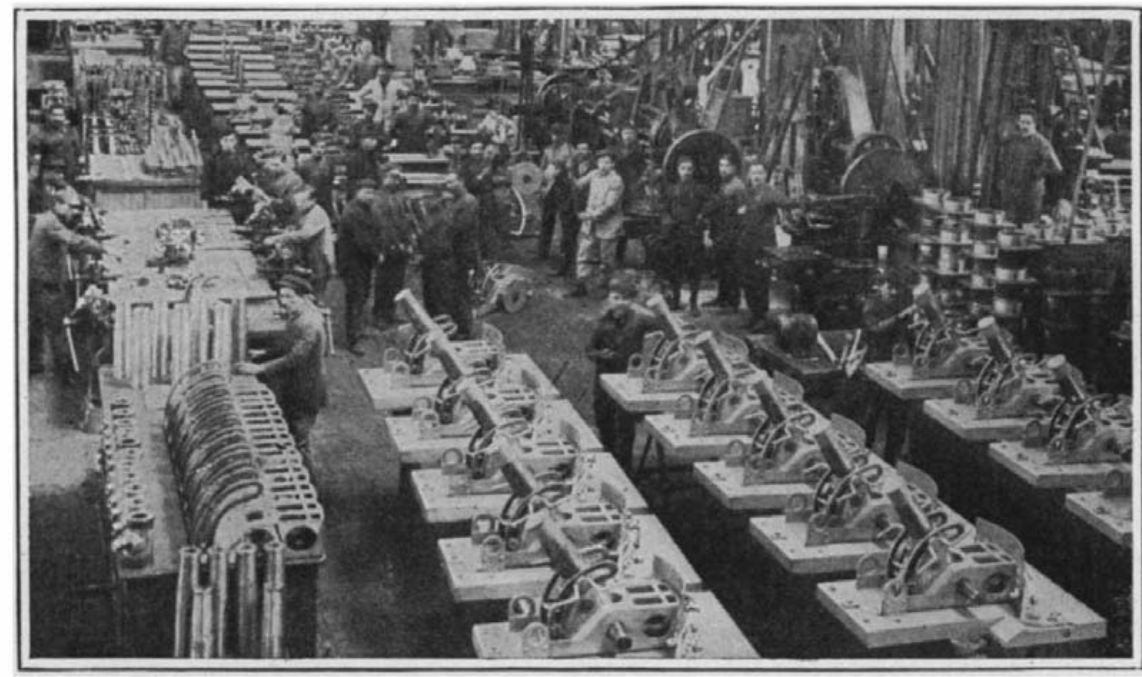

The tiny bomb-throwing mortars used in the trenches by the Italian army, completed and in course of manufacture

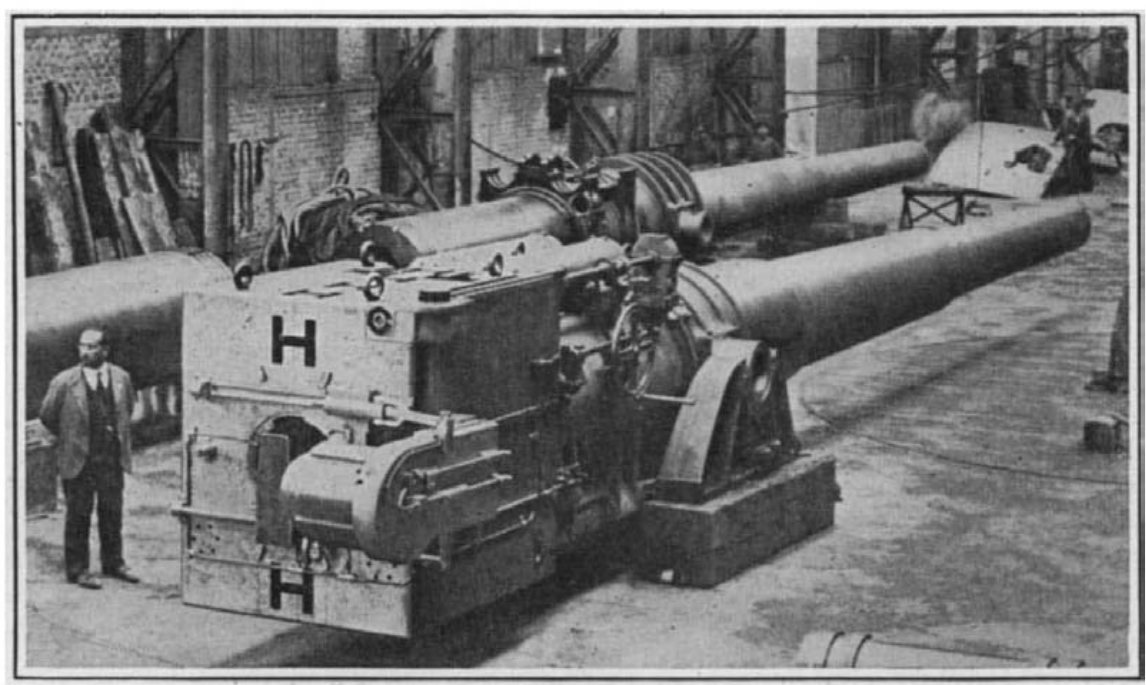

Box-like breech of a 381-millimeter, 40-caliber gun the terrific heat and pressure of their powder gases soon wear out the inner tubes especially of the greatest of these guns. By the Ansaldo company's own process, the inner tubes of these cannon are chilled and made to contract while the outer part is heated and made to expand. The in new inner tube, this also contracted by cold, is inserted into the heated and expanded jacket. After some hours the jacket cools and contracts while the inner tube grows warmer and expands, thus making a fit so tight that the inner tube is irremovable except by a repetition of this process.

For every one of these guns, large and small, the Ansaldo company makes the shells and cartridges. When it delivers a battcry of cannon to the army it sends it complete, ready to go into action, its guns mounted and thoroughly proven, its ammunition wagons laden with a sufficient quantity of well tested shells. The many factories in which these shells are made are filled with the latest machinery for turning, boring and forging metal. Thousands of women and girls are employed at the lathes, on the grinding and polishing machines, and in the exquisitely accurate work of calibration.

The historic words of Victor Emmanuel, "Italia fara' da Se," have never had a better exemplification than in this work that the Ansaldo company has accomplished since Italy went into the war. In the beginning it seemed an almost superhuman task; but the Italian engineers had the imagination and the courage to undertake it, and they are entitled to all the credit that the generals and ministers of their country so freely give them for their stupendous contribution to winning the war.

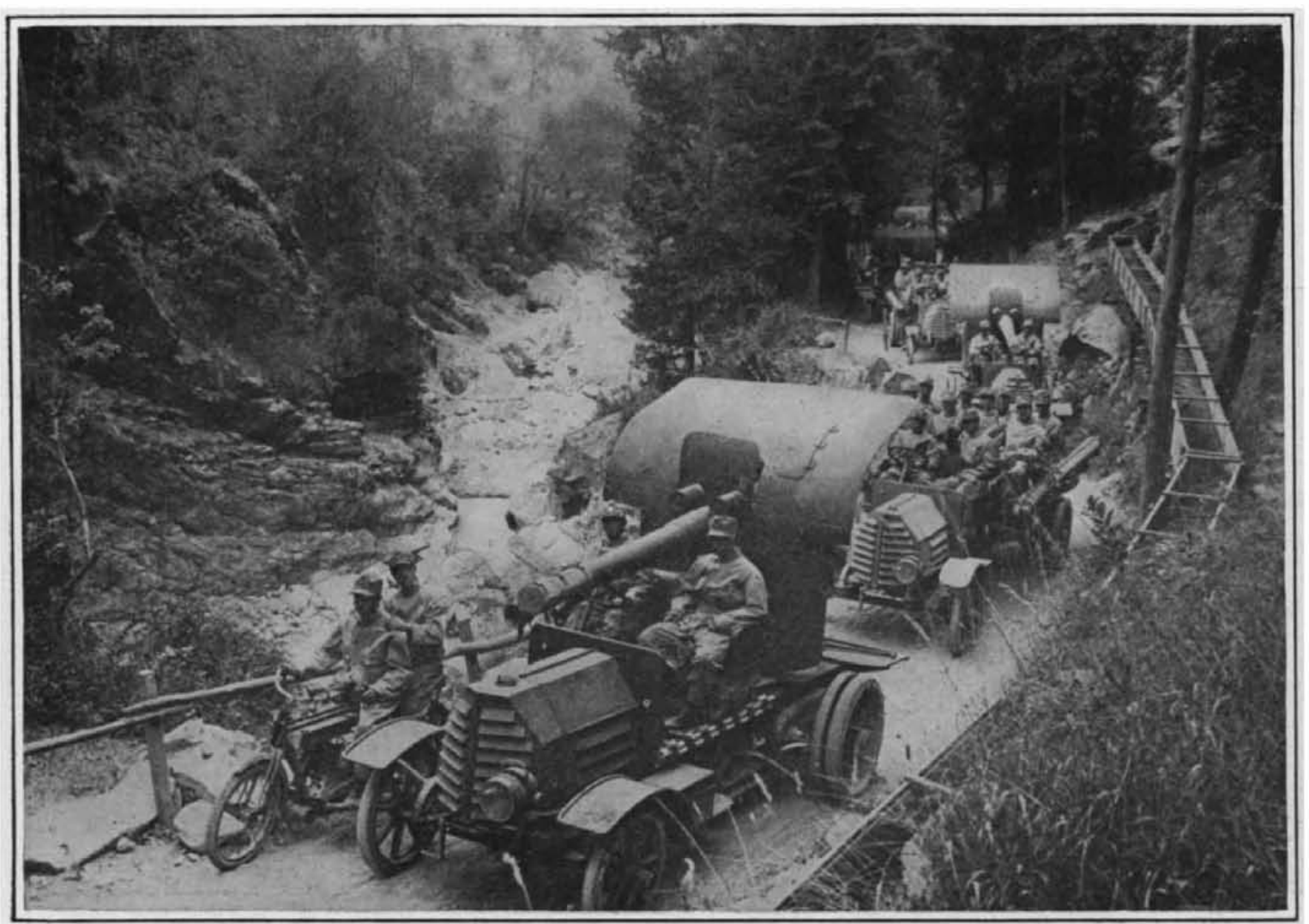

An automobile batterg of 102-millimeter guns on a mountain road at the Italian front

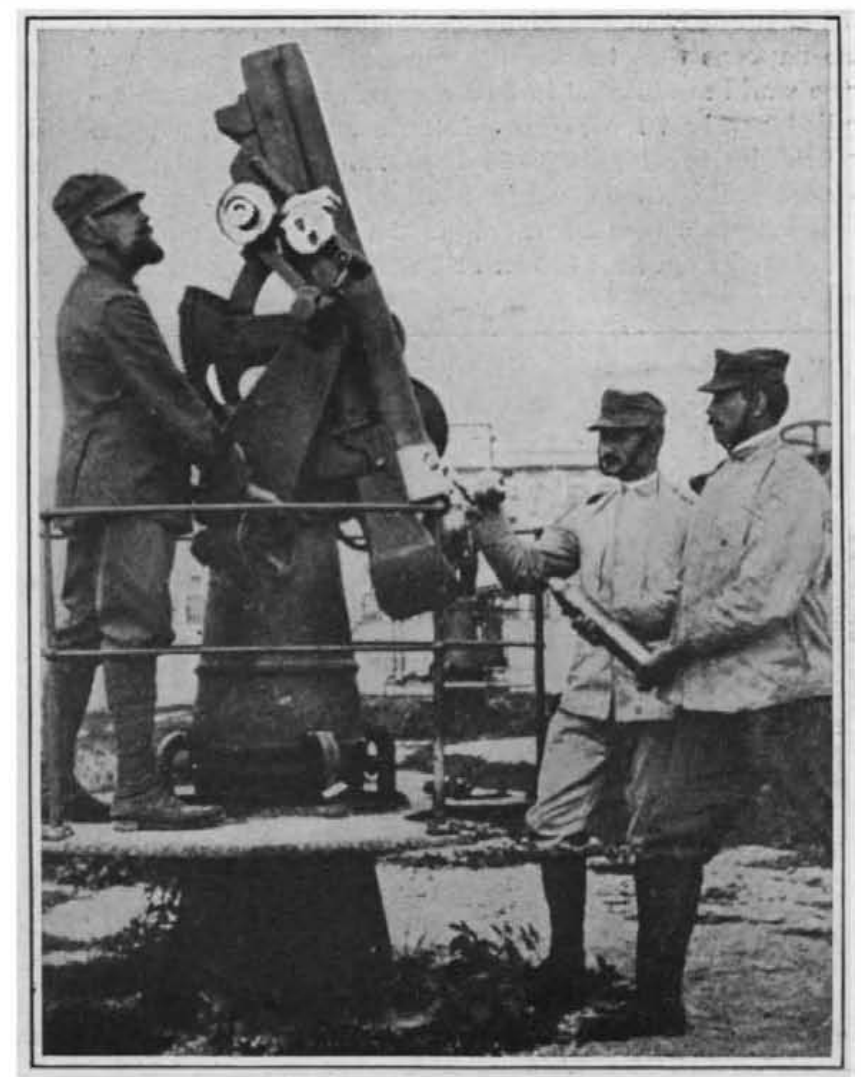

A 76-millimeter, 17-çaliber, anti-aircraft gun 